\title{
Remote water-quality sampling of Nevada pit lakes using unmanned aircraft systems
}

\section{Connor Newman ${ }^{1}$, Devin Castendyk ${ }^{2}$, Brian Straight ${ }^{3}$, Pierre Filiatreault ${ }^{4}$, Americo Pino ${ }^{5}$}

${ }^{1}$ Nevada Division of Environmental Protection, ${ }^{2}$ Golder Associates, ${ }^{3}$ University of Colorado at Boulder, ${ }^{4} \mathrm{BBA},{ }^{5} \mathrm{Hatch}$

\section{Background}

Mine pit lakes are becoming more common as metallurgical processing techniques allow for ore bodies of lower grade to be economically processed. Once mining ends and a pit lake is formed, water-quality samples may need to be collected for a variety of reasons including scientific research and regulatory compliance (Castendyk et al., 2015). In the State of Nevada, which hosts approximately 40 pit lakes (Newman, 2016) the Nevada Division of Environmental Protection (NDEP) is responsible for evaluating the water quality of pit lakes. Although regular monitoring is important, monitoring actions at pit lakes may pose a risk to human health and safety. In summer 2017, a sampling campaign was conducted in Nevada to apply an unmanned aircraft system (UAS) for pit-lake sampling (Figure 1).

\section{Methodology}

The sampling methodology applied in this study is the same as that described in Castendyk et al. (2017) for the use of a UAS to collect water-quality data. However, this sampling campaign consisted of the most samples collected to date by a UAS. The procedure consists of the following steps:

1. A multi-parameter sonde (YSI CastAway CTD) is lowered through the water column by the UAS (DII Matrice 600, $6 \mathrm{~kg}$ payload)

2. Physiochemical data from the sonde are evaluate to determine the limnologic structure of the pit lake

3. A Niskin sample bottle (General Oceanics 1010 Niskin bottle, $1.2 \mathrm{~L}$ ) is lowered using the UAS to the targeted depth and a messenger is deployed to close the sample bottle

4. The UAS returns the sample bottle to the user and the user collects the water-quality sample using appropriate techniques (Figure 3)

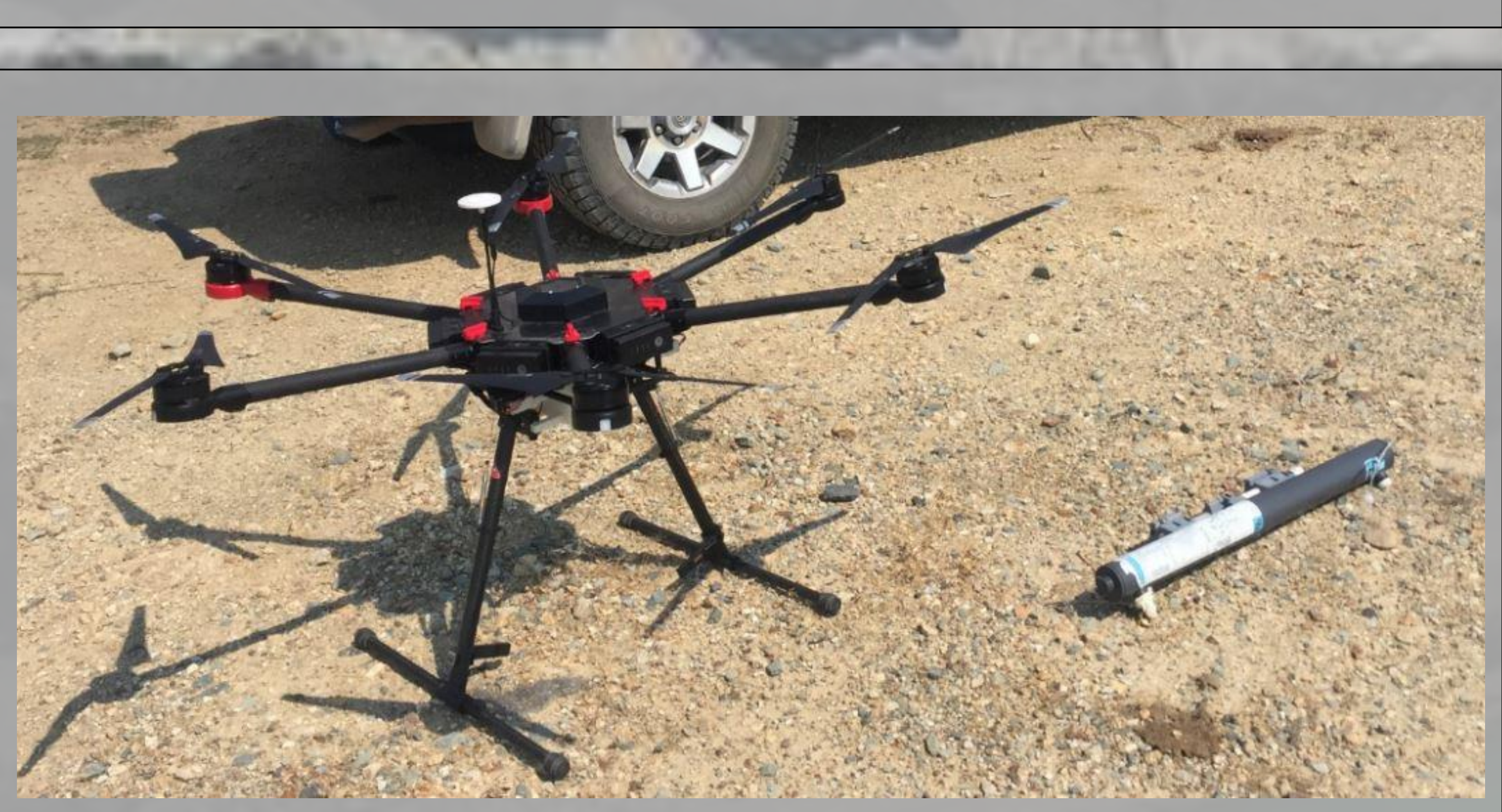

Figure 2: DJI Matrice with Niskin sample bottle

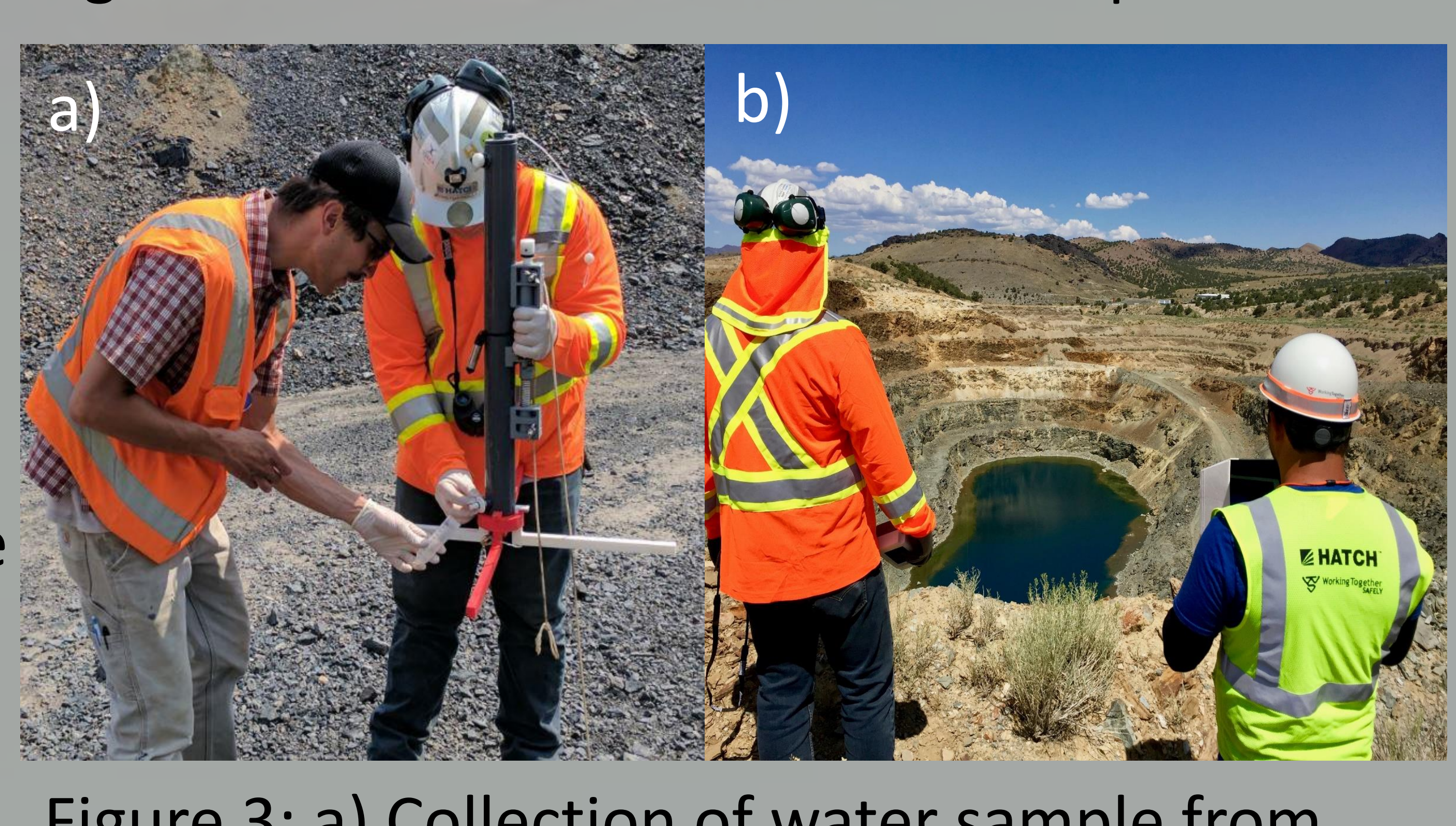

Figure 3: a) Collection of water sample from Niskin bottle; b) Operation of UAS to collect water sample

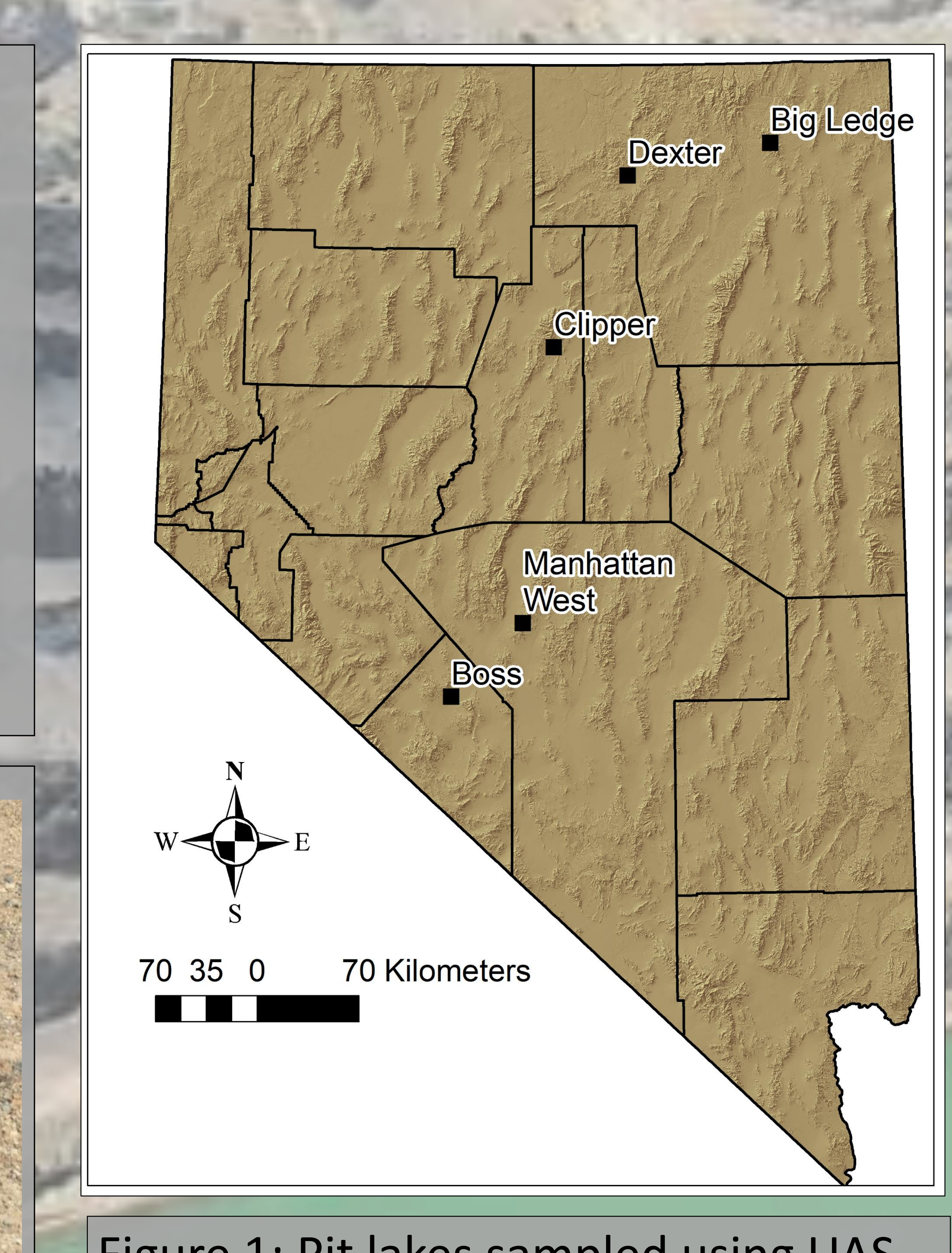

3. Results

Data collected by the sonde (Figure 4) illustrate how the UAS allows for rapid identification of distinct

hydrogeochemical layers within a given pit lake. This step of data collection allows identification of discrete sam depths for water-quality sampling. Following discrete sampling,

physiochemical parameters were monitored using hand-held multiparameter probes. Comparison of parameters measured by the sonde and discrete samples (Figures 5 and 6 ) shows that the sonde allows for accurate identification of distinct layers, although conductivity measurements compare better than temperature.

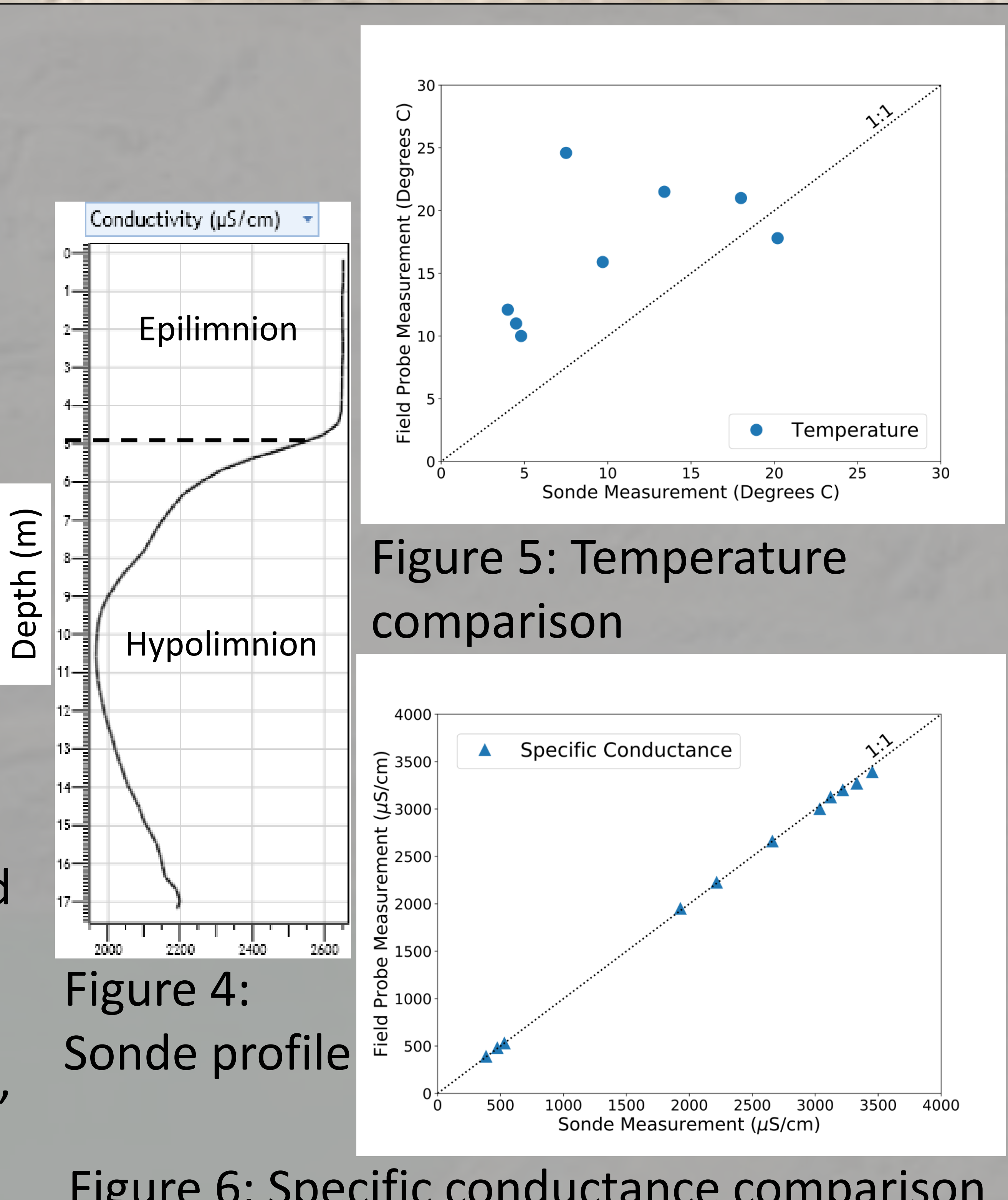

\section{Implications and Lessons Learned}

The sampling campaign illustrated how effective the methodology can be for sampling pit lakes, and identified aspects that should be included in planning of future campaigns:

The methodology is acceptable for regulatory procedures and allows for multiple samples to be collected while maintaining human and environmental safety.

- Planning requires identification of airspace restrictions and scheduling with appropriate authorities (FAA, military installations, etc.). Also, extra equipment (batteries, Niskin bottle parts, etc.) should be brought to allow for flexibility should equipment malfunction.
References
casenduk $0 .$, . Ear. LE.

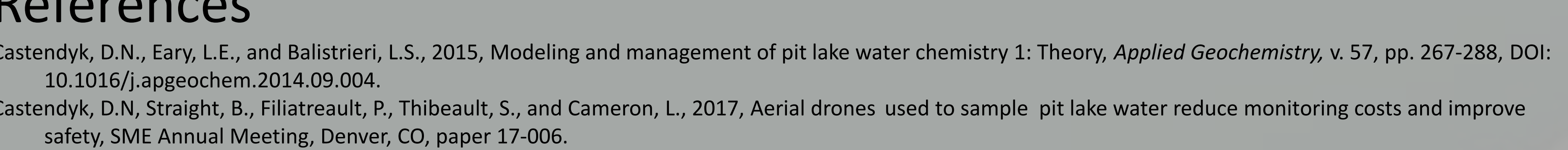

Acknowledgements pit lakes for allowing us to use the operators of the Manhattan West and Big Ledge We acknowledge financial 